\title{
FAKTOR - FAKTOR YANG MEMPENGARUHI NIAT BERWIRAUSAHA MAHASISWA
}

\author{
Walipah \\ Program Studi Pendidikan Ekonomi Universitas Kanjuruhan Malang \\ Jl. S. Supriadi No. 48 Malang \\ Naim \\ Program Studi Pendidikan Ekonomi Universitas Kanjuruhan Malang \\ Jl. S. Supriadi No. 48 Malang
}

\begin{abstract}
Socio-economic issues such as poverty, unemployment productive age are a major challenge for Indonesia when entering the free market and global competition. As one of the leading Human Resources, college needs to know the factors that influence students in entrepreneurship. Various factors that influence entrepreneurial intentions in students, especially the attitude and contextual factors. Population is Economic Education Student in Universtas Kanjuruhan Malang. Data were analyzed using multiple linear regression. The results of this study indicate that the attitude positive effect on entrepreneurial intention of students, while the contextual factors positively affects student entrepreneurial intention.
\end{abstract}

Keywords : Entreprenerial Intention, Attitude, Contextual Factor

DOI : http://dx.doi.org/10.21067/jem.v12i3.1461

Diterima: Agustus 2016; Direvisi: September 2016; Diterima : Oktober 2016

\section{PENDAHULUAN}

Era pasar bebas, kondisi yang di hadapi semakin diperburuk dengan situasi persaingan global (Asean Economic Community) yang akan menyandingkan lulusan Perguruan Tinggi Indonesia dalam kompetisi yang bebas dengan lulusan dari Perguruan Tinggi asing. Para Sarjana lulusan Perguruan Tinggi perlu diarahkan dan didukung untuk tidak hanya berorientasi sebagai pencari kerja namun harus siap menjadi pencipta pekerjaan serta menumbuhkan jiwa kewirausahaan mahasiswa. Upaya menumbuhkan jiwa kewirausahaan mahasiswa di perguruan tinggi merupakan alternative jalan keluar untuk mengurangi tingkat pengangguran serta permasalahan sosial lainnya.

* Corresponding Author. walipah@unikama.ac.id
Lulusan perguruan tinggi diharapkan dapat menjadi wirausahawan muda terdidik dan mampu merintis usahanya sendiri. Alma (2011) menjelaskan bahwa semakin maju suatu negara semakin banyak orang terdidik, dan semakin dirasakan pentingnya dunia wirausaha. Wirausaha merupakan salah satu pendukung yang menentukan maju mundurnya perekonomian, karena bidang wirausaha mempunyai kebebasanuntuk berkarya dan mandiri. Jika seseorang mempunyai kemauan dan keinginan serta siap untuk berwirausaha, berarti seseorang itu mampu menciptakan lapangan pekerjaan sendiri, dan tidak perlu mengandalkan orang lain maupun perusahaan lain untuk mendapatkan pekerjaan lagi.

Solusi yang bisa ditempuh untuk dapat keluar dari kompleksitas persoalan diatas menuntut, jiwa, pikiran, tindakan kreatif dan inovatif diantaranya melalui penciptaan wirausaha muda young entrepreneur) dalam 
jumlah dan kualitas yang memadai. Oleh karena itu, sedini mungkin para mahasiswa dibekali ketrampilan hidup (life skille) untuk menjadi bekal fundamental dalam menghadapi persaingan global.

Mengacu pada problema diatas, sebenarnya prodi pendidikan Ekonomi telah membekali mahasiswanya dengan ilmu entrepreneur dan kewirausahaan bahkan untuk memperkokoh pengetahuannya mahasiswa juga di wajibkan untuk melakukan kunjungan lapangan dan studi banding agar mereka lebih siap dalam mengembangkan dan mengaplikasikan jiwa entrepreneurnya dan tidak tergantung pada pekerjaan yang disediakan oleh perusahaan maupun pemerintah.

Namun, realita yang ditemukan dilapangan ternyata amat berbeda, mahasiswa sebaga "Sumber Daya Manusia" yang terdidik dan professional ternyata masih lemah dalam mengembangkan ilmu berwirausahanya bahkan tidak berani untuk memulai sejak dini, berbagai alasan yang dikemukakan, ada yang terkendala modal, nunggu mapan, tidak punya tempat dan masih banyak lagi, dengan fenomena ini maka peneliti menjadi tertarik untuk meneliti tentang faktor - faktor yang mempengaruhi niat kewirausahaan.

\section{TINJAUAN PUSTAKA \\ Niat Berwirausaha}

Niat berwirausaha dapat diartikan sebagai langkah awal dari suatu proses pendirian sebuah usaha yang umumnya bersifat jangka panjang (Lee, S.H. \& Wong, 2004). Selanjutnya dijelaskan bahwa niat berwirausaha mencerminkan komitmen seseorang untuk memulai usaha baru dan merupakan isu sentral yang perlu diperhatikan dalam memahami proses kewirausahaan pendirian usaha baru. Niat berwirausaha akhir-akhir ini mulai mendapat perhatian untuk diteliti karena diyakini bahwa suatu niat yang berkaitan dengan perilaku terbukti dapat menjadi cerminan dari perilaku yang se-sungguhnya. Theory of planned behavior merupakan teori yang dikembangkan oleh Ajzen yang merupakan penyempurnaan dari reason action theory yangdikemukakan oleh Fishbein dan Ajzen. Fokus utama dari teori planned behavior ini sama seperti teori reason action yaitu intensi individu untuk melakukan perilaku tertentu. Intensi dianggap dapat melihat faktor-faktor motivasi yang mempengaruhi perilaku. Intensi merupakan indikasi seberapa keras orang hrndak berusaha untuk mencoba dan berapa besar usaha yang akan dikeluarkan individu untuk melakukan suatu perilaku

\section{Faktor-Faktor yang Mempengaruhi Niat Berwirausaha \\ Faktor Sikap \\ Percaya diri}

Menurut Bygrave (1994) menyatakan bahwa wirausahawan (entrepreneur) adalah seseorang yang mampu melihat peluang dan berusaha menciptakan cara untuk mendapatkan hasil dari peluang tersebut. Sementara itu, Meng \& Liang (1996) merangkum pandangan dan definisi wirausaha dari beberapa ahli dan mendifinisikannya sebagai orang yang memiliki karakteristik sebagai berikut kreatif, inovatif dan proaktif; berani mengambil resiko; memiliki visi dan misi yang jelas; memiliki kebutuhan berprestasi tinggi; tekun dan memiliki rasa tanggung-jawab yang tinggi; percaya diri; serta bersemangat dan penuh antusias.

\section{Berorientasi pada Tugas dan Hasil}

Seseorang yang selalu mengutamakan tugas dan hasil adalah orang yang selalu mengutamakan nilai-nilai motif prestasi, berorientasi pada laba, ketekunan dan ketabahan, tekad kerja keras, mempunyai dorongan kuat, energik, dan berinisiatif. Berinisiatif artinya selalu ingin mencari dan memulai sesuatu. Untuk memulai diperlukan adanya niat dan tekad yang kuat serta karsa yang besar. Sekali sukses atau berprestasi maka sukses berikutnya akan menyusul, sehingga usahanya semakin maju dan berkembang. Dalam kewirausahaan, peluang hanya diperoleh apabila terdapat inisiatif. Perilaku inisiatif ini biasanya diperoleh melalui pelatihan dan pengalaman mereka selama bertahun-tahun, dan pengembangannya diperoleh dengan cara disiplin diri, berpikir kritis, tanggap, dan semangat berprestasi. Berbagai motivasi akan muncul dalam bisnis jika kita berusaha menyingkirkan prestise. Kita akan mampu bekerja keras, enerjik, tanpa malu dilihat teman, asal yang kita kerjakan adalah halal.

Geoffrey G. Meredith dalam Suryana, (2001) mengemukakan ciri-ciri dan watak kewirausahaan yaitu Berorientasi pada tugas dan hasil yaitu : (1). Memenuhi kebutuhan akan 
prestasi, (2). Orientasi pekerjaan berupa laba, tekun dan tabah, tekad kerja keras. (3). Berinisiatif

\section{Pengambilan Resiko}

Kemauan dan kemampuan untuk mengambil suatu resiko merupakan salah satu nilai utama dalam kewirausahaan. Dalam situasi resiko dan ketidakpastian inilah wirausaha mengambil keputusan yang mengandung potensi kegagalan atau keberhasilan. Pilihan terhadap resiko ini sangat bergantung pada: Daya tarik setiap alternative 1). Siap untuk mengalami kerugian 2). Kemungkinan relatif untuk gagal atau sukses 3) Kemampuan untuk mengambil resiko ditentukan oleh: Keyakinan pada diri sendiri. 4) Kesediaan menggunakan kemampuan dalam mencarai peluang 5). dan kemungkinan untuk memperoleh keuntungan. Kemampuan menilai situasi resiko secara realistis. 6). Wirausaha penuh resiko dan tantangan, seperti persaingan, harga turun naik, barang tidak laku dan sebagainya. Namun semua tantangan ini harus dihadapi dengan penuh perhitungan. Oleh sebab itu, pengambil resiko ditemukan pada orang-orang yang inovatif dan kreatif yang merupakan bagian terpenting dari perilaku kewirausahaan.

Geoffrey G. Meredith dalam Suryana, (2001) mengemukakan ciri-ciri dan watak kewirausahaan yaitu berani mengambil resiko yaitu Berani dan mampu mengambil resiko kerja dan Menyukai pekerjaan yang menantang

\section{Keorisinilan}

Nilai inovatif, kreatif dan fleksibilitas merupakan unsur-unsur keorisinilan seseorang. Wirausaha yang inovatif adalah orang yang kreatif dan yakin dengan adanya cara - cara baru yang lebih baik. Wirasasmita (2003) ciri cirinya sebagai berikut : (1). Tidak perna puas dengan cara yang di lakukan saat ini, meskipun cara tersebut cukup baik. (2). Selalu menuangkan imajinasi dalam pekerjaannya (3). Selalu ingin tampil berbeda atau memanfaatkan perbedaan. Maksud dari teori di atas adalah tidak hanya mengikuti orang lain, tetapi memiliki pendapat sendiri dan terdapat kemampuan untuk melaksanakan sesuatu.

\section{Berorientasi Masa Depan}

Orang yang berorientasi ke masa depan adalah orang yang memiliki persfektif dan pandangan ke masa depan. Karena memiliki pandangan yang jauh ke masa depan, maka ia selalu berusaha untuk berkarsa dan berkarya. Kuncinya adalah kemampuan untuk menciptakan sesuatu yang baru dan berbeda dengan yang sudah ada saat ini. Meskipun terdapat resiko yang mungkin terjadi, ia tetap tabah untuk mencari peluang dan tantangan demi pembaruan masa depan. Pandangan yang jauh ke depan membuat wirausaha tidak cepat puas dengan karsa dan karya yang sudah ada saat ini. Oleh sebab itu ia selalu mempersiakannya dengan mencari peluang. Untuk menghadapi pandangan jauh ke depan, seorang wirausaha akan menyusun perencanaan dan strategi yang matang, agar jelas langkah-langkah yang akan dilaksanakan.

\section{Faktor Kontekstual \\ Academic Support}

Academic support Menurut Bandura dalam Alwisol, (2009) dukungan akademik mengacu pada faktor-faktor yang berkaitan dengan dukungan bagi seorang pelajar untuk mencapai dan menyelesaikan tugas-tugas studi dengan target hasil dan waktu yang telah ditentukan. Pada dunia akademik, terdapat PP No. 60 Tahun 1999, kebebasan akademik merupakan kebebasan yang dimiliki oleh anggota sivitas akademika untuk melaksanakan kegiatan yang terkait dengan pendidikan dan pengembangan ilmu pengetahuan dan teknologi secara bertanggungjawab dan mandir, adanya peraturan tentang kebebasan akademik merupakan implementasi bentuk dukungan akademik pada mahasiswa.

\section{Social Support}

Social support adalah salah satu istilah untuk menerangkan bagaimana hubungan sosial menyumbang manfaat bagi kesehatan mental atau kesehatan fisik pada individu. Baron \& Byrne (2000) mendefinisikan social support sebagai kenyamanan fisik dan psikologis yang diberikan oleh teman-teman dan keluarga individu tersebut. Dukungan sosial merupakan bantuan yang berasal dari orang yang memiliki hubungan sosial akrab dengan individu yang menerima bantuan. Bentuk dukungan ini dapat berupa infomasi, tingkah laku tertentu, ataupun materi yang dapat menjadikan individu yang menerima bantuan merasa disayangi, diperhatikan dan bernilai. 


\section{Environmental Support}

Schneider dalam (Ellias \& Loomis, 2000), menjelaskan bahwa lingkungan dianggap dapat menciptakan penyesuaian diri yang cukup sehat bagi pelajar bila individu dibesarkan dalam keluarga dimana terdapat keamanan, cinta, respek, toleransi dan kehangatan.Lebih lanjut dijelaskan bahwa lingkungan tempat belajar merupakan lingkungan kedua setelah lingkungan keluarga yang membentuk individu.Kegiatan kewirausahaan juga dapat dijelaskan oleh pengaruh dari sekitar lingkungan bisnis. Para ahli telah menekankan bahwa kebijakan pemerintah, karakteristik konteks lokal (misalnya ketersediaan infrastruktur logistik, investor keuangan, dan eksternalitas) dan lebih khusus mekanisme dukungan universitas mempengaruhi kegiatan kewirausahaan (Morris \& Lewis, 1995) Environmental support adalah keadaan lingkungan yang baik dan teratur dalam infrastruktur fisik, aset fisik perusahaan, laboratorium libang dan hal-hal yang tidak berwujud (manusia, modal, rutinitas, sumber daya) memiliki peranan dalam mendorong intensi berwirausaha (Niosi \& Bas, 2001). Khususnya dukungan keuangan, seperti ketersediaan modal ventura (Beck, Demirguc Kunt, \& Maksimovic, 2005), dan layanan yang mendukung kewirausahaan, seperti memberikan kesempatan pelatihan, pinjaman infrastruktur, fisik dan persaingan rencana (Feldman, 2001).

\section{METODE}

Penelitian ini merupakan penelitian jenis eks-planatif karena bertujuan untuk meneliti karakteristik variabel dan hubungan antar variabel yang telah ada.Penelitian ini juga bertujuan untuk menjelaskan penyebab dan dampak hubungan. Populasi penelitian ini adalah mahasiswa Universitas Kanjuruhan Program Studi Pendidikan Ekonomi Angkatan 2012-2014 yang telah menempuh mata kuliah kewirausahaan. Teknik smapling menggunakan accidental sampling. Jumlah responden yang ditargetkan adalah sejumlah 150 orang mahasiswa. Kegiatan pengumpulan data menggunakan kuesioner terstruktur dan dilakukan langsung oleh tim peneliti dengan dibantu 2 orang enumerator yang direkrut dari mahasiswa dan sebelumnya para enumerator telah ditraining terlebih dahulu untuk penyamaan persepsi.

\section{Pengukuran Variabel}

Dalam penelitian ini, data primer diperoleh melalui wawancara langsung di lapangan dengan menggunakan kuesioner penelitian terstruktur, yang terbagi dalam 3 bagian: faktor sikap, faktor kontekstual dan niat kewirausahaan. Pengukuran sikap individual menggunakan indeks TPB (theory planned behavior) bagian I: occupational status choice index yang bertujuan mengukur sikap seseorang untuk berwirausaha. Instrumen ini berisi pernyataan mengenai autonomy/ authority, economic challenge, self realization, security dan workload, avoid responsibility, social career dan perceived confidence (Gurbuz \& Aykol, 2008). Variabel academic support diukur menggunakan skala dari Autio et al., 2001 dalam Gurbuz \& Aykol (2008) yang terdiri dari 4 pernyataan, variabel social support menggunakan 3 item pernyataan dari skala Gurbuz \& Aykol (2008) dan environmental support menggunakan skala dari Verheul et al. (2005) dalam Gurbuz \& Aykol (2008) yang terdiri dari 4 pernyataan. Akhirnya, untuk mengukur variabel niat kewirausahaan (enterpreneurial intention), responden diminta menentukan tingkat ketertarikan mereka untuk mendirikan usaha sendiri setelah mereka lulus sarjana dengan 3 pertanyaan yang diadopsi dari Gerry et al. (2008), yang menunjukkan tingkat intensi mereka untuk berwirausaha. Secara keseluruhan, untuk faktor sikap, kontekstual dan niat kewirausahaan, pernyataan diukur dengan menggunakan 5-point Likert scale, dimana responden diminta untuk menjawab dengan pilihan angka antara 1-5 (1= sangat tidak setuju, dan $5=$ sangat setuju). Adapun indikator variabel dijabarkan sebagai berikut

Tabel 1

Indikator Penelitian

\begin{tabular}{|c|c|}
\hline Variabel & Indikator \\
\hline \multirow{7}{*}{$\begin{array}{l}\text { Sikap } \\
\text { (Bygrave } \\
\text { (1994) }\end{array}$} & 1 Autonomy \& Authority \\
\hline & $\begin{array}{l}2 \text { Economic opportunity \& } \\
\text { Challenge }\end{array}$ \\
\hline & 3. Security and Work Load \\
\hline & 4. Avoid Responsibility \\
\hline & $\begin{array}{l}\text { 5. Self Realization and } \\
\text { Participation }\end{array}$ \\
\hline & $\begin{array}{l}\text { 6. Social Environment dan } \\
\text { career }\end{array}$ \\
\hline & 7. Perceived confidence \\
\hline
\end{tabular}




\begin{tabular}{|l|l|}
\hline $\begin{array}{l}\text { Faktor } \\
\text { Kontekstual } \\
\text { (Alwisol, } \\
2009)\end{array}$ & 1 Academic Support \\
\cline { 2 - 2 } & 2 Social Support \\
\cline { 2 - 2 } & 3 Environmental support \\
\hline
\end{tabular}

Sumber : Data diolah tahun 2016

\section{HASIL DAN PEMBAHASAN}

Untuk menganalisa pengaruh sikap dan terhadap faktor kontekstual terhadap minat berwirausaha menggunakan metode Regresi linear berganda dengan mengggunakan software SPSS versi 20.00 .

Berikut hasil output spss dalam bentuk tabel;

Tabel 2

Hasil Analisis

Uji Regresi Linier Berganda

\begin{tabular}{rlrr}
\hline Model & & \multicolumn{1}{c}{ S } & \multicolumn{1}{c}{ Sig. } \\
\hline & & \multicolumn{1}{c}{ B } & Std. Error \\
\hline 1 & (Constant) &, 610 &, 543 \\
& X1 & 4,091 &, 000 \\
& X2 & 3,681 &, 000 \\
\hline
\end{tabular}

Sumber : Data diolah tahun 2016

Lokasi penelitian merupakan lokasi tempat proses pembelajaran kewirausahaan berlangsung dan Penelitian ini dilaksanakan di Prodi Pendidikan Ekonomi FKIP Universitas Kanjuruhan Malang.

Pengaruh sikap individual terhadap niat kewirausahaan telah diteliti sejumlah peneliti dengan menggunakan unsur-unsur sikap yang terdapat dalam Theory of Planned Behavior (TPB) dari Ajzen dan Fishbein (1985) dalam Gurbuz \& Aykol (2008) yang mencakup autonomy/authority, economic challenge, self realization, dan perceived confidence, security dan workload, avoid responsibility, dan social career. Dalam penelitian ini sejumlah unsur dari variabel sikap yaitu memiliki otoritas dan otonomi (authority and autonomy), menginginkan pekerjaan yang menantang dan bernilai ekonomi tinggi (economic opportunity), menyukai pekerjaan yang berdaya cipta dan kreatif (self-realization) dan memiliki keyakinan tentang kemampuan berwira-usaha (perceived confidence) sesuai dengan hipotesis, terdukung dalam penelitian ini.Temuan ini men-dukung penelitian terdahulu yang dilakukan oleh Gurbuz \& Aykol (2008) dan Tjahjono \& Ardi (2010).Perceived confidence dan authority dan autonomy merupakan dua elemen yang memiliki pengaruh yang cukup kuat terhadap niat kewirausahaan. Ini berarti peningkatan niat kewirausahaan mahasiswa dapat dilakukan dengan meningkatkan keyakinan diri mereka melalui penguasaan ketrampilan berwira-usaha dan juga memberikan kebebasan penuh pada mahasiswa untuk menentukan pilihan karir mereka sendiri di masa depan sesuai keinginan sikap, penelitian ini tidak menemukan adanya pengaruh yang signifikan dari unsur avoid responsibility dan social environment dan carrier terhadap niat kewirausahaan mahasiswa, yang mana kedua unsur tersebut dihipotesiskan ber-pengaruh secara negatif terhadap niat kewirausahaan.

Faktor kontekstual dalam model penelitian ini adalah pendidikan kewirausahaan, dukungan akademik, dukungan sosial dan kondisi lingkungan usaha.Hipotesis berkaitan dengan dukungan akademik (academic support) dan dukungan sosial (social support) terhadap niat kewirausahaan mahasiswa terdukung dalam penelitian ini.Hasil penelitian ini menunjukkan bahwa sistem PBM yang dapat memotivasi munculnya ide-ide kreatif, penyediaan infrastruktur untuk berlatih kewirausahaan di kampus serta adanya contoh kesuksesan berwirausaha di lingkungan kampus dapat meningkatkan niat kewirausahaan mahasiswa. Demikian juga, dorongan dari unsur-unsur lingkungan sosial seperti motivasi dari teman dekat, orang-orang yang dianggap penting serta keluarga ternyata terbukti berpengaruh secara positif terhadap niat kewirausahaan mahasiswa. Oleh karena itu, untuk mendorong timbulnya niat mahasiswa untuk berwirausaha setelah lulus sarjana nanti, perlu mendapat dukungan dari pihak keluarga dan teman-teman terdekat. Lingkungan dunia usaha dalam penelitian ini tidak terbukti berpengaruh terhadap niat kewirausahaan mahasiswa.

Hasil analisis regresi memperlihatkan sejumlah unsur dari variabel sikap, yaitu authority dan autonomy, economic opportunity, self realization dan perceived confidence sesuai dengan hipotesis yang dirumuskan, terdukung dalam penelitian ini. Keempat elemen sikap tersebut terbukti berpengaruh secara positif terhadap niat kewirausahaan mahasiswa yaitu sebesar 40,91\% dengan nilai signifikansi sebesar $0,000<0,05$, dan dari keempat elemen sikap tersebut, perceived confidence dan authority dan 
autonomy merupakan dua elemen yang memiliki pengaruh yang cukup kuat terhadap niat kewirausahaan.

Sedangkan faktor Kontekstual Pengujian hipotesis dengan menggunakan analisis regresi memperlihatkan semua hipotesis berkaitan dengan pengaruh faktor kontekstual terhadap niat kewirausahaan mahasiswa terdukung dalam penelitian ini. Hasil uji statistik menemukan adanya pengaruh yang positif dan signifikan antara variabel academic support dan social support dengan niat kewirausahaan mahasiswa yaitu sebesar $36,81 \%$ dengan nilai signifikansi sebesar $0,000<0,05$.

\section{SIMPULAN}

Berdasarkan hasil penelitian ini, dapat ditarik beberapa kesimpulan:

Faktor-faktor sikap terbukti berpengaruh secara signifikan dan positif terhadap niat berwirausaha mahasiswa. Faktor kontekstual terbukti berpengaruh secara signifikan dan positif terhadap niat kewirausahaan mahasiswa.

\section{DAFTAR PUSTAKA}

Alma, B. 2011.Kewirausahaan.Bandung: Alfabeta.

Alwisol 2009, Psikologi Kepribadian, Edisi Revisi Malang :UMM Press

Robert A. Baron dan Donn Byrne,2004, Psikologi social, Universitas Negeri Malang Jakarta Erlangga

Beck, T., Demirguc- Kunt, A., and V. Maksimovic.2005 "Financial and Legal Constraints to Firm Growth: Does Firm Size Matter?", Journal of Finance, 2005, pp: $137-177$

Bygrave, W.D. 1994. The Portable MBA in Entrepreneurship. Singapore: John Wiley $\&$ Son, Inc.

Dunn, T.A. \& Holtz-Eakin, D.J. 2000. Financial Capital, Human Capital and the Transition to Self-Employment: Evidence from Intergenera-tional Links. Journal of Labor Economics, 18(2): 282305.

Elias, SM \& Loomis R.J, 2000. Using an academic self efficacy sale to addres University major persistence Journal of college student development

Feldman, M.P. 2001.The entrepreneurial event revisited: firm formation in a regional context,. Industrial and Corporate Change, Vol. 10, No. 4, pp: 861-875.

Gurbuz, G. \& Aykol, S. 2008, Entrepreneurial Intentions of Young Educated Public in Turkey. Journal of Global Strategic Management, 4(1): 47-56.

Gerry. C, Susana. C. \& Nogueira. F. 2008. Tracking Student Entrepreneurial Potential: Personal Attributes and the Propensity for Business Start-Ups after Graduation in a Portuguese University. International Research Journal Problems and Perspectives in Management, 6(4): 45-53.

Herdiman, F.S. 2008.“Wirausahawan Muda Mulai dari Lingkungan

Keluarga".http://jurnal

nasional.com/media, diunduh pada tanggal 12 Maret 2011.

Isdianto, B., Willy, D. \& Mashudi, M.R. 2005. Orientasi Sistem Pendidikan Desain Interior terhadap Motivasi Kewirausahaan Mahasiswa (Mencari Hambatan dan Stimulus). Laporan Penelitian. Bandung: Institut Teknologi Bandung.

Lee, S.H. \& Wong, P.K. 2004. An Exploratory Study of Technopreneurial Intentions: A Career AnchorPerspective. Journal of Business Venturing, 19(1): 7-28.

Lieli Suharti dan Hani Sirine ,September 2011" Faktor-Faktor yang Berpengaruh Terhadap Niat Kewirausahaan (Entrepreneurial Intention) "Jurnal Manajemen Dan Kewirausahaan, Vol.13,No.2

http://puslit2.petra.ac.id/gudangpaper/file s/2050.pdf

Meng, L.A, \& Liang, T.W, 1996. Entrepreneurs, Entrepreneurship and Entreprising Culture. Paris: Addison-Wisley Publishing Company

Morris, M., \& Lewis, P. 1995. The determinants of entrepreneurial activity. European Journal of Marketing, Vol. 29, No. 7, pp: $31-48$.

Niosi, J., \& Bas, T.G. 2001. The competencies of regions: Canada's clusters in Biotechnology. Small Business Economics, Vol. 17, No. 1-2, pp: 31-42.

Nishanta, B. 2008.Influence of Personality Traits and Socio-demographic Background of Undergra-duate Students on 
Motivation for Entrepre-neurial Career:

The Case of Srilanka. Paper was presented at the Euro-Asia Management Studies Association (EAMSA) Conference, Japan

Suryana. 2001. Kewirausahaan. Salemba Empat: Jakarta

Tjahjono, H.K. \& Ardi, H. 2008. Kajian Niat Mahasiswa Manajemen Universitas Muham-madiyah Yogyakarta untuk
Menjadi Wirausaha. Utilitas Jurnal Manajemen dan Bisnis, 16(1): 46-63

Yuyun Wirasasmita, 2003, Pemikiran Kewirausahaan, Kreatifitas Inovasi, dan Kewirausahaan, Bandung Laboratorium Manajemen, fakultas Ekonomi Unpad Wu, S. \& Wu, L. 2008.The Impact of Higher Education on Entrepreneurial Intentions of University Students in China.Journal of Small Business and Enterprise Development, 15(4): 752-774. 